\title{
Ruthenium-Catalyzed Cycloaddition of Benzocyclobutenones with Diols
}

Gategory

Metal-Catalyzed

Asymmetric

Synthesis and

Stereoselective

Reactions

\section{Key words}

ruthenium catalysis

cycloaddition

benzocyclo-

butenones

diols

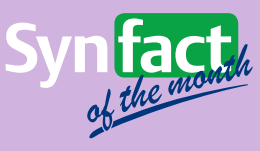

Selected examples:<smiles>COc1cccc2c1C(=O)C1(O)CCCCC1(O)C2</smiles>

$88 \%$ yield, $d r>20: 1$<smiles>COc1cccc2c1C(=O)C1(O)CCCC1(O)C2</smiles>

$64 \%$ yield, $d r>20: 1$<smiles>COc1cccc2c1C(=O)[C@@]1(O)CCCC[C@@]1(O)[C@H]2OC</smiles>

$82 \%$ yield, $d r>20: 1$<smiles>COc1cccc2c1C(=O)C1(O)CCCCCC1(O)C2</smiles>

$82 \%$ yield, $d r>20: 1$

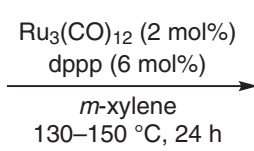<smiles>COc1cccc2c1C(=O)C1(O)CCCCC1(O)C2=O</smiles>

$89 \%$ yield, $\mathrm{dr}>20: 1$<smiles>COc1cccc2c1C(=O)C1(O)CCc3ccccc3[C@@]1(O)CC2</smiles>

$86 \%$ yield, $d r>20: 1$ single regioisomer<smiles></smiles><smiles>O=C1c2ccccc2CC2(O)CCCCC12O</smiles>

$95 \%$ yield, $d r>20: 1$<smiles>COc1cccc2c1C(=O)[C@@]1(O)CCCC(C)(C)C1(O)C2</smiles>

$61 \%$ yield, $d r>20: 1$ single regioisomer

Proposed mechanism:

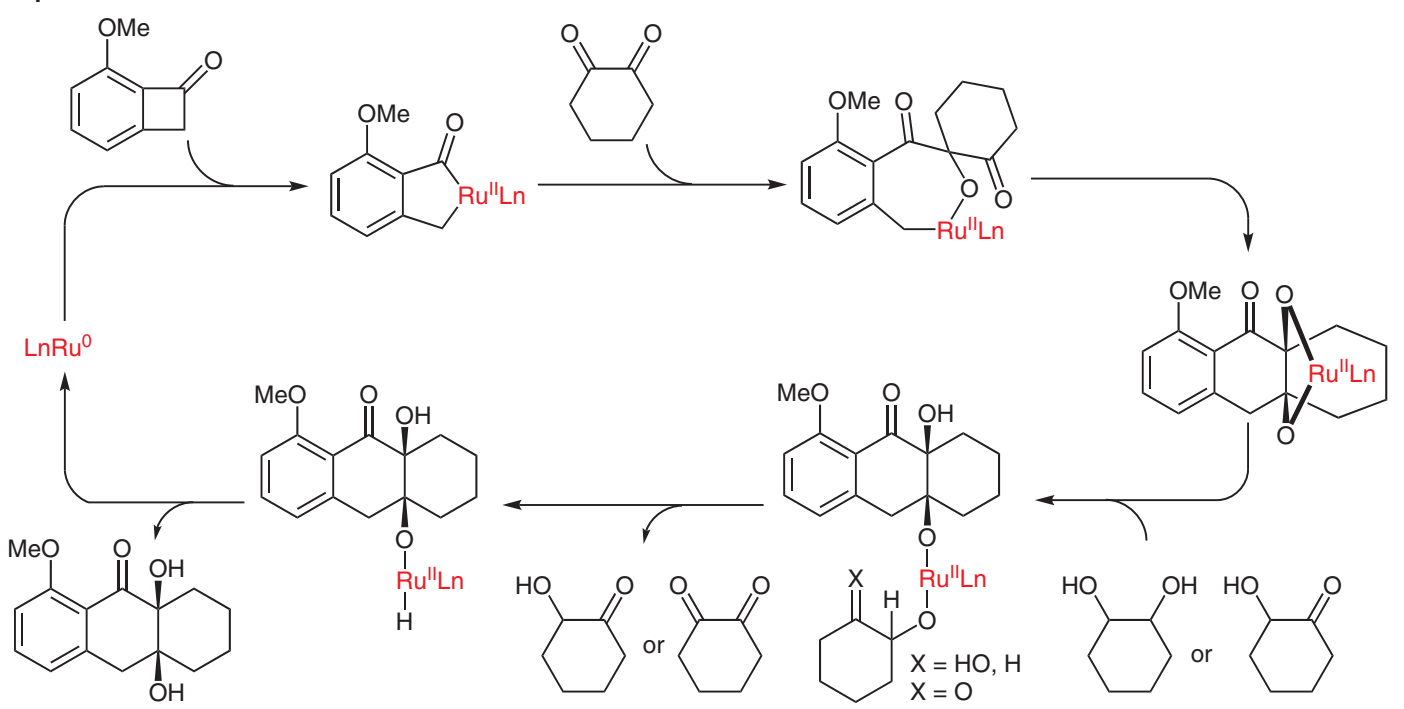

Significance: The authors have reported intermolecular cycloadditions through formal insertion of saturated $\mathrm{C}-\mathrm{H}$ bonds into $\mathrm{C}-\mathrm{C} \sigma$-bonds. A ruthenium(0)/dppp complex catalyzed the diastereoselective coupling reactions of benzocyclobutenones to adjacent saturated carbon centers in diols. SYNFACTS Contributors: Hisashi Yamamoto, Takahiro Sawano Synfacts 2017, 13(11), 1153 Published online: 19.10.2017 Dol: 10.1055/s-0036-1591339; Reg-No.: H12717SF
Comment: The cycloaddition via ruthenacycles from the benzocyclobutenones and dehydrogenation of the alcohols provides a convergent method for the construction of type II polyketide substructures. 